\title{
Performance analysis of supply chains under customer demand information sharing using role play game
}

\author{
T. Chinna Pamulety and V. Madhusudanan Pillai*
}

Department of Mechanical Engineering, National Institute of Technology Calicut, Calicut - 673 601, Kerala, India

\begin{tabular}{|c|c|}
\hline$\overline{\text { A R T I C L E I N F O }}$ & A B S T R A C T \\
\hline $\begin{array}{l}\text { Article history: } \\
\text { Received } 25 \text { October } 2011 \\
\text { Received in revised form } \\
\text { November, 2, 2011 } \\
\text { Accepted February, } 32012 \\
\text { Available online } \\
\text { 9 February } 2012 \\
\text { Keywords: } \\
\text { Supply Chain } \\
\text { Bullwhip Effect } \\
\text { Imperfect ADI } \\
\text { (R, S) Policy }\end{array}$ & $\begin{array}{l}\text { Supply chain is a network of organizations that work together and performs various business } \\
\text { functions such as procurement of raw materials, converting the raw material into semi-finished } \\
\text { or finished goods and distributing the same to their ultimate customers. Presence of bullwhip } \\
\text { effect in a supply chain is costly and degrades the performance of the supply chain. Reduction } \\
\text { in bullwhip effect can improve the efficiency or profitability of a supply chain. The objective } \\
\text { of this paper is to know the impact of imperfect Advance Demand Information (ADI) sharing } \\
\text { on bullwhip effect in a four-stage serial supply chain and to evaluate the supply chain } \\
\text { performance by conducting an experiment similar to the beer distribution game. The } \\
\text { performance measures used are variance of orders placed by each stage, fill rate, total inventory } \\
\text { at each stage and total holding cost of the supply chain. Results show that imperfect ADI } \\
\text { improves the performance of the supply chain. The performance of the supply chain is also } \\
\text { evaluated under order up to level }(\mathrm{R}, \mathrm{S}) \text { policy with safety stock and it is found that the } \\
\text { performance of supply chain is better when inventory policy used. }\end{array}$ \\
\hline
\end{tabular}

\section{Introduction}

Supply chain consists of various stages that are directly or indirectly involved in fulfilling the customer requirements. Increase in the variance of orders placed by each stage when we move from downstream stage to upstream stages is referred to as bullwhip effect. Downstream stage is the direction towards the end customer; and upstream stage is the direction towards the end supplier. Forrester was the first person who noticed this phenomenon (Wu \& Katok, 2006). In some industries, this effect is also known as whiplash or whipsaw effect. Increase in variance of orders creates excessive inventories or shortages, poor customer services because of unavailability of products or long backorders, insufficient or excessive capacities and also unstable or uncertain production planning. Thus, the bullwhip effect is costly and harmful to the efficiency of the supply chain. The causes of the bullwhip effect are: lack of customer demand information (Sterman, 1989), demand forecast updating, order batching, variation in prices, rationing and shortage gaming (Lee et al., 1997), replenishment rule (Dejonckheere et al., 2003) and lead time (Simchi Levi et al., 2008). Procter \& Gamble $(\mathrm{P} \& \mathrm{G})$ observed this phenomenon in one of their best selling products called

* Corresponding author. Tel: 09895367804

E-mail: vmp@nitc.ac.in (V.M. Pillai) 
Pampers where as Hewlett-Packard (HP) observed it in their printer product (Lee et al., 1997, 2004). They tried to reduce it and could see the increase in their profit. Reduction in bullwhip effect has significant impact on the profitability of the whole supply chain (Bottani et al., 2010). Its importance to a firm depends on the business environment in which it is working; elimination of bullwhip effect can increase the profit of the firm (Metters, 1997).

The bullwhip effect in a supply chain is because of the information distortion from downstream to upstream stages. It may also result from overestimation because of forecasting the demand at a stage by using the received forecasted orders from its downstream stage. It is like keeping the safety stock over safety stock (Sucky, 2009). Therefore, sharing of the end customer demand information with each stage is essential for reducing the bullwhip effect. Different forms of sharing the end customer demand information includes sharing customer demand distribution called as imperfect ADI in this research work, Periodic customer demand and also combination of Periodic customer demand and ADI. Information on future customer orders is called as ADI. If it is certainly going to happen then it is called perfect ADI, otherwise it is called as imperfect ADI. It may be generated through internet retailing or from sales representatives (Tan et al., 2007).

The performance of the supply chain can be analyzed either analytically or experimentally or simulation. Sterman (1989) was the first person who analyzed the performance of the supply chain experimentally using the beer distribution game. This experiment involves a supply chain with four players namely retailer, wholesaler, distributor and factory. Each player receives the orders from their downstream and takes decision about the order quantity independently without consulting the other players. The players reported that the reason for large variance in their orders is due to their inability to predict the pattern of customer demand. Impact of customer demand distribution, PoS data and inventory information sharing are studied by Croson and Donohue (2003, 2006). Steckel et al., (2004) also used beer distribution game to know the impact of Point of Sale (PoS) and the lead time in the performance of supply chain.

There are a lot of analytical studies for describing the effect of lead time on bullwhip effect. Bullwhip effect increases with lead time (Simchi-Levi et al., 2008). Wang et al., (2008) studied the impact of lead time on bullwhip effect and total inventory. Fluctuations in orders are more if the lead time is longer and is the evidence of the bullwhip effect. Longer lead times will also increase the total inventory. Agrawal et al., (2009) studied the impact of information sharing and lead time on the bullwhip effect and found that lead time reduction reduces the bullwhip effect than the information sharing.

The present experimental work is different from the existing work in terms of lead time, demand distribution and its variability. As per the knowledge of the authors of this paper, the experiments designed in the previous research work considered longer lead time (4 periods) which is the cause of bullwhip effect and is also the cause of complexity in decision making. So, one of the main objectives of this work is to test the impact of imperfect ADI on bullwhip effect in supply chain by considering small lead time (1 period) and without backorders. No back orders are assumed because customers may not be willing to wait for their needs in the present competitive world. The excess demand which has not met is considered as lost sales. The second objective of the present study is to measure the performance of the supply chain by calculating various performance measures which were not focused in the previous research work. The performance measures used are variance of orders placed by each stage, fill rate, total inventory at each stage and total holding cost of the supply chain.

The paper is organized as follows: Experimental procedure is described in Section 2; the performance measures are explained in Section 3. Section 4 explains statistical tests conducted and Section 5 describes the supply chain under $(\mathrm{R}, \mathrm{S})$ policy with safety stock inventory control system at each stage. Finally, discussion and conclusions are given in Section 6. 


\section{Experimental procedure}

We have developed a supply chain role play game software for conducting experiments similar to the beer distribution game. The Beer Distribution Game is a simulation of a supply chain with four comakers (retailer, wholesaler, distributor and factory). The details of the game can be seen in Sterman (1989 and 2009). The developed software simulates the operational decisions taken at each stage of a four stage serial supply chain and evaluates its performance. The names of the four stages in the supply chain considered are retailer $(i=1)$, wholesaler $(i=2)$, distributor $(i=3)$ and factory $(i=4)$. At each review period (one week), customer places an order to the retailer; the retailer to the wholesaler and so on. The retailer ships the quantity against the order placed by the customer. The shipment quantity depends on the inventory available. It can be same as the order received if sufficient inventory is available; otherwise whatever inventory is available will be shipped. The retailer also decides the size of the order to be placed to the next higher level that is, the wholesaler. Similar operational decisions such as shipment quantity and order size are taken at every stage. Order and shipment flows are shown in Fig.1.

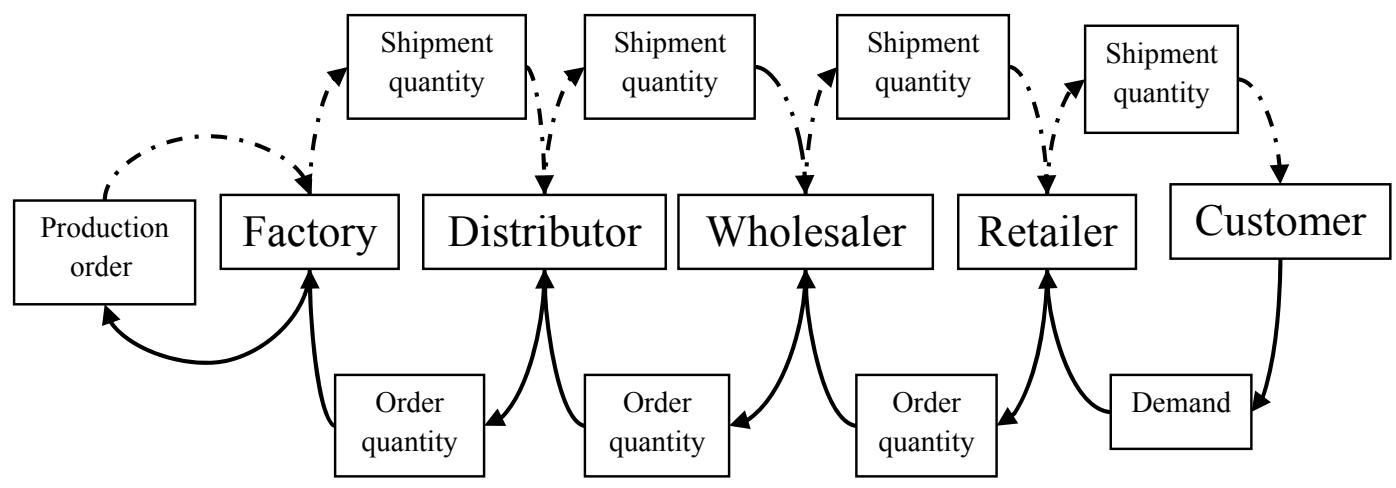

Fig.1. Order and shipment flow in supply chain

The main objective while taking the order decision at each stage is to maximize the fill rate and to minimize the inventory held. The order placed by stage $i$ at the end of the period $t$ reaches $(i+1)$ stage at the beginning of period $(t+1)$ and the quantity shipped by stage $(i+1)$ reaches stage $i$ in the beginning of period $(t+2)$ for $i=1,2,3$. It is assumed that the order is placed at the end of a period as this is happening after meeting the demand of the period. The factory issues production order to replenish the inventory and it will be received immediately. The sequence of events occurring at each period at each stage are: (i) the shipments from upstream stage are received and placed in inventory; (ii) the orders from downstream stages are received and met from the available inventory and (iii) an order is placed to next upstream stage. In this software, manager or instructor can set the supply chain under different parameters such as lead time, with and without backorders, with or without information sharing. Information sharing includes imperfect ADI, Periodic customer demand and combination of both. Customer demand distribution and its parameters are shared among all stages under imperfect ADI. Whereas, the actual customer demand faced by the retailer at each period is shared in periodic customer demand information sharing. Various performance measures provided by the software are variance of orders placed by each stage, fill rate, total inventory at each stage and total holding cost of the supply chain (THCS).

In the present experiments, 88 members have participated. Each one acts as a stage in the supply chain and formed 22 identical supply chains. They are students from under graduate, post graduate, and management studies. Many of them are from Industrial Engineering and Management specialization. Eleven supply chains are analyzed without information sharing; and the remaining with imperfect ADI sharing. Training for a period of 10-week play was given to the participants before proceeding to the actual experiments. The duration of the actual experiment was not revealed 
to the participants and it was conducted for a period of 55 weeks. In those 55 weeks, first 6 periods are considered as trial period and the periods from 7 th to 48th are considered for performance analysis purpose. This is considered from the existing literature for reducing the end game effect (Steckel et al., 2004). The performance measures used for evaluation are explained in the next Section. The assumptions of the present study are:

1. Customer demand is for a single product and follows normal distribution with parameters 20,5 .

2. There are no capacity constraints and storage space constraints at each stage in the supply chain.

3. Beginning inventory at each stage is 40 units.

4. Holding cost is $\$ 0.5$ per unit per period for each stage.

\section{Performance measures:}

Various performance measures used in the performance analysis of the supply chains are variance of orders placed by each stage, fill rate, total inventory at each stage and total holding cost of the supply chain (THCS). They are explained below.

\section{Notations used:}

$i$ - Stage index in the supply chain, $i=1,2,3,4$

$I^{i}-$ Total inventory of stage $i$

$t$ - Time period in weeks

$k$ - Time period required for an order to reach higher stage

$L$ - Time period required for shipment quantity to reach lower stage

$h_{i}-$ Holding cost per unit per period at stage $i$

$n$ - Number of time periods

THCS - Total Holding Cost of a Supply chain

$S Q_{t}^{i}-$ Quantity shipped by stage $i$ in period $t$

$D_{t}-$ Customer demand in period $t$

$O_{t}^{i}$ - Order quantity of stage $i$ in period $t$

$I_{t}^{i}$ - Ending inventory of stage $i$ in period $t$

\subsection{Variance of orders placed by each stage}

It is used to measure the bullwhip effect. The bullwhip effect is having negative impact on the profitability of the supply chain. It is good to have less variance of orders in the supply chain.

Variance of orders placed by stage, $i, \sigma_{i}^{2}=\frac{\sum_{i=1}^{n}\left(O_{t}^{i}-\bar{O}\right)^{2}}{n-1}$,

\subsection{Fill rate}

The fill rate is defined as a fraction of demand met from the shelf. This is an appropriate performance measure, which determines the customer service level or delivery level of a supply chain. Maximizing the customer service level is one of the objectives of supply chain management.

$$
\begin{aligned}
& \text { Fill rate }=\frac{\text { Demand met }}{\text { Demand arisen }} \\
& \text { Fill rate }=\frac{\sum_{t=1}^{n} S Q_{t}^{i=1}}{\sum_{t=1}^{n} D_{t}} .
\end{aligned}
$$




\subsection{Total inventory at each stage}

Total inventory at stage $i, I^{i}=\sum_{t=1}^{n} I_{t}^{i}$ where

$I_{t}^{i}=\left\{\begin{array}{ccc}\max \left(0,\left(I_{t-1}^{i}+S Q_{t-L}^{i+1}-D_{t}\right)\right) & \text { for } & i=1 \\ \max \left(0,\left(I_{t-1}^{i}+S Q_{t-L}^{i+1}-O_{t-k}^{i-1}\right)\right) & \text { for } & i=2,3 \\ \max \left(0,\left(I_{t-1}^{i}+O_{t-L}^{i}-O_{t-k}^{i-1}\right)\right) & \text { for } & i=4\end{array}\right.$

\subsection{Total holding cost of the supply chain}

It is the holding cost of all stages in the supply chain.

$$
\text { THCS }=\sum_{i=1}^{4} \sum_{i=1}^{n} h_{i} I_{t}^{i}
$$

The above performance measures are calculated for each supply chain experiment conducted and results are shown in Fig. 2 to Fig. 7. Fig. 2 and Fig. 3 show variance of orders placed by each stage without and with information sharing respectively. Inventory performance is shown in Fig. 4 and Fig. 5, where as the overall performance of supply chain is shown in Fig. 6. Fill rate of supply chains are given in Fig. 7. The average value of each performance measure is calculated by considering the eleven supply chains with information sharing and the eleven without information sharing. The results are tabulated in Table.1.

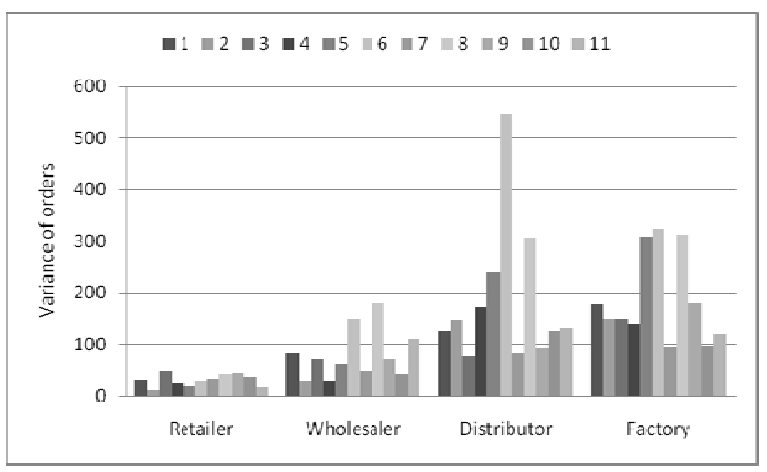

Fig. 2. Variance of orders placed by each stage under no information sharing

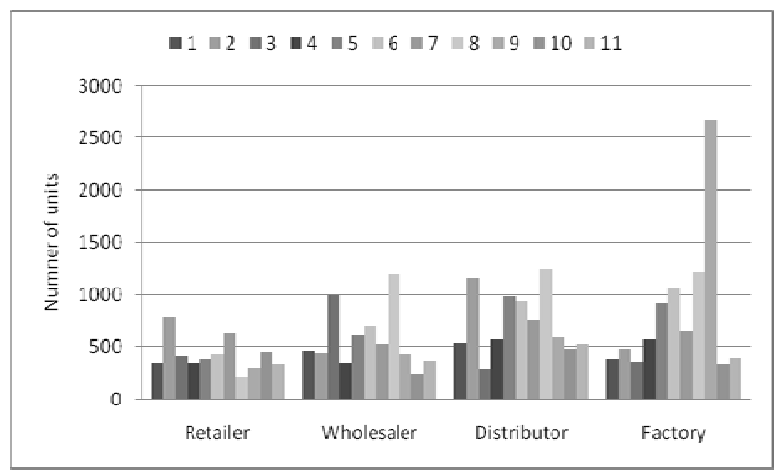

Fig.4. Total inventory at each stage under no information sharing

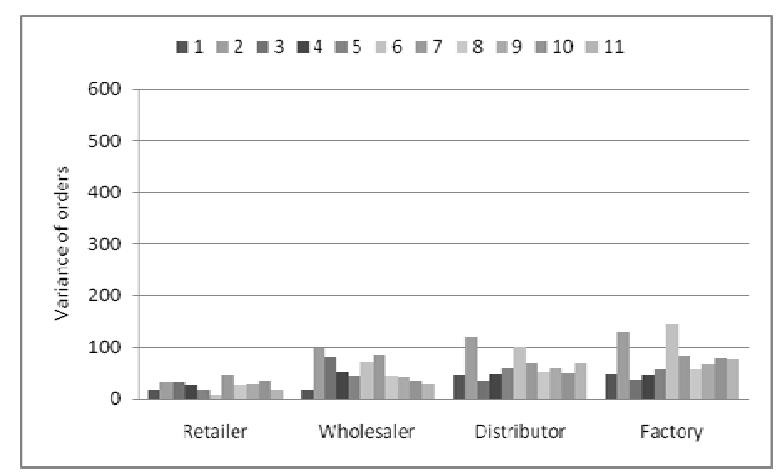

Fig. 3. Variance of orders placed by each stage under imperfect ADI sharing

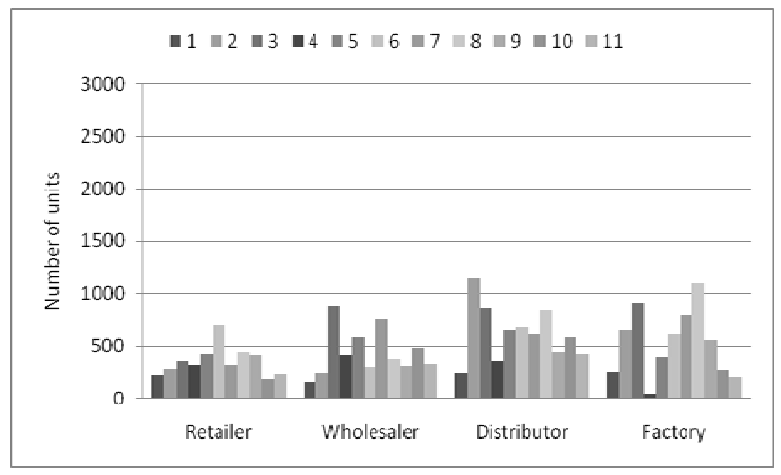

Fig. 5. Total inventory at each stage under imperfect ADI sharing 


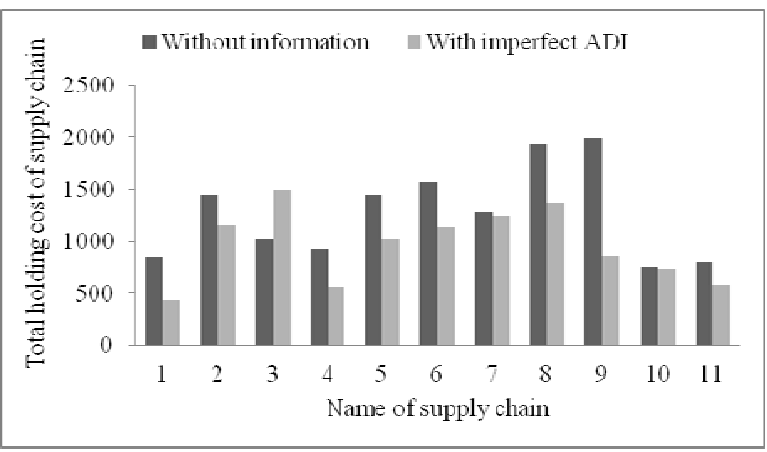

Fig.6. Total holding cost of supply chain

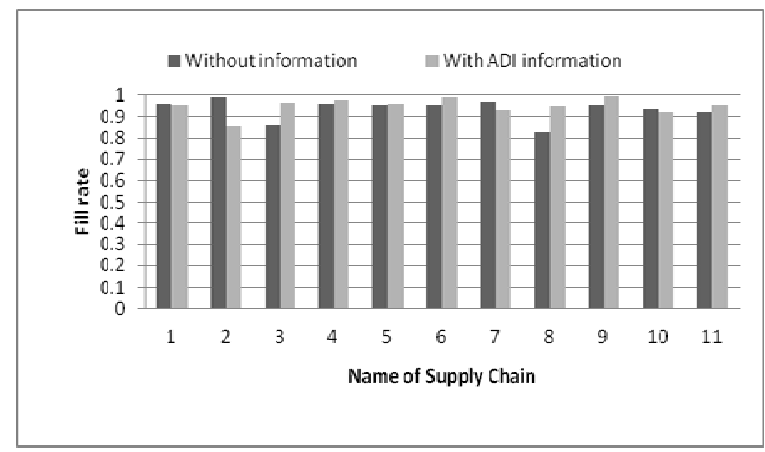

Fig.7. Supply chain fill rate

\section{Table 1}

Average values of performance measures of the supply chains

\begin{tabular}{llccc}
\hline \multirow{2}{*}{ Performance measures } & \multicolumn{4}{c}{ Stage Name } \\
\cline { 2 - 5 } & Retailer & Wholesaler & Distributor & Factory \\
\hline & \multicolumn{3}{c}{ Supply chain under no information sharing } \\
\hline Variance of orders placed by each stage & 30.683 & 79.946 & 186.384 & 186.917 \\
Fill rate & 0.935 & & & \\
Total end period inventory at each stage & 418.818 & 574.273 & 732.182 & 820.364 \\
THCS & 1272.82 & & & \\
\hline & \multicolumn{3}{c}{ Supply chain under imperfect ADI sharing } \\
\hline Variance of orders placed by each stage & 26.545 & 54.344 & 64.649 & 75.445 \\
Fill rate & 0.949 & & \\
Total end period inventory at each stage & 351.455 & 437.636 & 616.182 & 524.000 \\
THCS & 962.818 & & \\
\hline
\end{tabular}

Table 1 shows the mean of all performance measures across eleven supply chains. From the mean value of performance measures, it is observed that the variance of orders placed by each stage with no information sharing is higher than with information sharing and is high in upstream stages in the supply chain. The reason for this is that the decisions taken at upstream stages are based on the orders received from their downstream stages instead of actual customer demand arisen at the retailer stage. This indicates that information on customer demand helps to take better decisions at each stage in the supply chain. From the average values of each performance measure we can say that the performance of the supply chain with information sharing is better than without information sharing with respect to all performance measures. But, the appropriate conclusion can be drawn from the statistical tests and are explained in Section 4.

\section{Statistical Tests conducted}

The following statistical tests are conducted for the experimental results to establish conclusions on the impact of imperfect ADI in the performance of serial supply chain

\subsection{Statistical test for the presence of bullwhip effect}

One of the aims of this study is to test the presence of bullwhip effect under imperfect ADI sharing with small lead time and without back orders. The null hypothesis is given below.

Null hypothesis: The Bullwhip effect will not occur under imperfect ADI with small lead time and no backorders.

The experimental results of variance of orders placed by each stage are shown in Fig. 3. Since the variable under consideration (variance) has continuous distribution, sign test can be used to test the 
presence of bullwhip effect (Siegel and Castellan, 1988; Croson and Donohue, 2006; Wu and Katok, 2006). The procedure of this test is as follows. For each supply chain, we code, an increase in the variance of orders placed between consecutive stages in a supply chain as a success and a decrease as a failure. If the variance of orders between stages is same, we code it as zero. The sum of the possible successes and failures form the sample size $(\mathrm{N})$. The probability of success or failure is 0.5 . Success is represented by a plus (+) sign and a failure with a minus (-) sign. If $X$ represents the number of plus signs, then the probability of getting $X$ or more plus signs is calculated from the binomial distribution. If this probability is less than the significance level $(\alpha=0.05)$ fixed, the null hypothesis must be rejected. The details of the sign test can be found in Siegel and Castellan (1988) and Johnson (2004). The total number of (+), (-) and zero codes in a supply chain can be three. Thus in eleven supply chains, the total codes will be 33. For the problem described here, $N=33$ and we got $X$ as 26 , and hence the $\mathrm{P}(X \geq 26)$ is 0.00065 which is less than the significance level $(\alpha=0.05)$ fixed to the present problem. So the above hypothesis must be rejected and we conclude that bullwhip effect will occur under ADI sharing with small lead time and no backorders. Similarly, it is possible to establish that bullwhip effect is present in no information sharing case also.

\subsection{Statistical test for the impact of imperfect ADI on each stage variance of orders}

An F-test is conducted to know the impact of imperfect ADI sharing on each stage variance of orders. In this test, F-value is calculated for each stage of each supply chain by taking the ratio of variance of orders without information to with imperfect ADI sharing and eleven F-tests are conducted for each stage. The results are shown in Table 2. From the F-test analysis, the four supply chains at the retailer stage, five supply chains at the wholesaler stage, nine supply chains at the distributor stage and eight supply chains at factory stage have shown the significant difference in their variance of orders with imperfect ADI sharing. The test is conducted at $90 \%$ confidence interval (CI). This test concludes that imperfect ADI sharing reduces the variance of orders at higher stages in the supply chain.

\section{Table 2}

Details of F-test for each stage variance of orders

\begin{tabular}{|c|c|c|c|c|c|c|c|c|}
\hline \multirow{3}{*}{$\begin{array}{l}\text { Name of } \\
\text { supply chain }\end{array}$} & \multicolumn{8}{|c|}{ F-value $(0.1,41,41)=1.4979 ; \mathrm{CI}=90 \%$} \\
\hline & \multicolumn{8}{|c|}{$\begin{array}{l}\text { H0: No difference in variances } \\
\text { H1: There is difference in variances }\end{array}$} \\
\hline & Retailer & Decision & Wholesaler & Decision & Distributor & Decision & Factory & Decision \\
\hline 1 & 1.709 & Reject & 4.806 & Reject & 2.869 & Reject & 3.620 & Reject \\
\hline 2 & 0.342 & & 0.304 & & 1.226 & & 1.155 & \\
\hline 3 & 1.432 & & 0.885 & & 2.261 & Reject & 3.970 & Reject \\
\hline 4 & 0.899 & & 0.560 & & 3.612 & Reject & 3.103 & Reject \\
\hline 5 & 1.092 & & 1.457 & & 3.940 & Reject & 5.326 & Reject \\
\hline 6 & 3.395 & Reject & 2.068 & Reject & 5.381 & Reject & 2.250 & Reject \\
\hline 7 & 0.735 & & 0.567 & & 1.190 & & 1.131 & \\
\hline 8 & 1.573 & Reject & 4.153 & Reject & 5.840 & Reject & 5.296 & Reject \\
\hline 9 & 1.580 & Reject & 1.704 & Reject & 1.564 & Reject & 2.700 & Reject \\
\hline 10 & 1.030 & & 1.191 & & 2.541 & Reject & 1.210 & \\
\hline 11 & 1.013 & & 3.872 & Reject & 1.860 & Reject & 1.572 & Reject \\
\hline
\end{tabular}

\subsection{Statistical test for the impact of imperfect ADI on Total Holding Cost of Supply chain (THCS)}

A t-test for difference in means for the total holding cost in the supply chains is conducted by taking mean over eleven supply chains.

Null Hypothesis: The mean difference in the total holding cost of supply chain under no information sharing and with imperfect ADI sharing is zero 
The $t$ - value for the experiments conducted is calculated based on the following formula (Montgomery, 2001)

$$
t=\frac{\overline{x_{1}}-\overline{x_{2}}}{S_{p} \sqrt{\frac{1}{n_{1}}+\frac{1}{n_{2}}}}
$$

where $\overline{x_{1}}, \overline{x_{2}}$ are mean value of THCS under no information sharing and with imperfect ADI sharing, respectively.

$\mathrm{n}_{1}, \mathrm{n}_{2}$ are sample size of no information sharing and with imperfect ADI sharing group, respectively.

$S_{p}=\sqrt{\frac{\left(n_{1}-1\right) S_{1}^{2}+\left(n_{2}-1\right) S_{2}^{2}}{n_{1}+n_{2}-2}}$

$S_{1}^{2}, S_{2}^{2}$ are variance of THCS under no information and imperfect ADI sharing, respectively.

The above parameter values are calculated for the present problem and are given below.

$\overline{x_{1}}=1251.027 ; \overline{x_{2}}=962.818$ and $t=1.692$

Critical value of $t$ from student's $t$-distribution table is $\mathrm{t}_{0.1,20}=1.325$

Since $t$ calculated is greater than $t$ critical, the null hypothesis should be rejected with $10 \%$ significance level and we can conclude that the total holding cost of supply chain with imperfect ADI sharing is lesser than the supply chain under no information sharing.

\section{Performance analysis of the supply chain under $(R, S)$ with safety stock inventory control policy}

This policy consists of two parameters: order interval or review period $(R)$ and maximum inventory or order up to level $(S)$. At each review period, an order is placed such that the inventory position reaches to the maximum inventory level. Hence, the size of an order to be placed at each review period depends on the inventory position at that time period. Inventory position at a particular period is equal to sum of the on-hand inventory and the outstanding orders. The parameter $R$ for the present work is 1 week and the parameter $S$ is calculated in the following way.

Order up to level, $S=$ Average demand during review period and lead time + safety stock

For the problem considered in this work, the customer demand follows normal distribution, the maximum inventory position, $S$ is

$$
S=\bar{M}+Z \sigma
$$

where $\bar{M}$ is the average demand in the review period and lead time $=40$ units;

$\sigma$ is the standard deviation of review period and lead time demand $=\sqrt{2} \times 5=7.07$ and $Z$ is the standard normal deviate.

The maximum fill rate obtained in the experiments has considered as the fill rate required with this inventory control policy in the supply chain. The safety stock is determined based on this fill rate.

Fill rate is the fraction of demand met from the shelf and can also defined as follows

$$
\text { Fill rate }=1-\frac{\text { stockout quantity }}{\text { total number of units demanded }}
$$

Fill rate $=1-\frac{E\left[(M-S)^{+}\right]}{Q}$

where $X^{+}=\max (X, 0)$

$E\left[(M-S)^{+}\right]=\sigma L(z)$

where $L(z)$ is loss function and $L(z)=E\left[(z-Z)^{+}\right]$ 
The number of units planned to meet the average demand $(Q)$ in a review cycle is equal to the average demand required during review period and is 20 units.

$\sigma L(z)=(1-$ Fill rate $) Q$

For fill rate of 0.949 (highest fill rate from the experimental average performance measures given in Table 1), $\sigma L(z)=(1-0.949) \times 20=1.02, L(z)=1.02 / 7.07=0.1443$. Z from tables (some functions of the unit normal distribution, Silver et al., (1998)) for the above L (z) is 0.694.

The expected safety stock $=Z \sigma=0.694 \times 7.07=4.906$ (say 5 ) units

Order up to level or maximum inventory level, $S=40+5=45$ units

This policy is followed at each stage in the supply chain and is simulated for 55 weeks. The customer demand for each week of 55 weeks is same as used in experimentation. The performance of the supply chain under this policy is evaluated and the performance measures are calculated using equations (1) to (4). This analysis is carried out by considering the periods from 7 to 48 and the results are compared with experimental results. The results are tabulated in Table 3.

Table 3

Performance analysis by following $(R, S)$ with safety stock inventory policy Variance of orders placed by each stage

\begin{tabular}{|c|c|c|c|}
\hline Retailer & Wholesaler & Distributor & Factory \\
\hline 16.20 & 15.73 & 15.36 & 16.13 \\
\hline \multicolumn{4}{|c|}{ Inventory at the end of the each stage } \\
\hline 346 & 355 & 352 & 280 \\
\hline Fill rate & in $\$=666.5$ & & \\
\hline
\end{tabular}

\section{Discussion and conclusions}

The performance of a four-stage serial supply chain is analyzed with and without imperfect ADI sharing, by conducting experiments similar to the beer distribution game. The results are shown in Fig. 2 to Fig. 7. It is clear from the Fig. 2 and Fig. 3 that the magnitude of variance of orders placed with information sharing is less than without information sharing. The F-test conducted for each stage variance of orders shows that the magnitude of variance of orders at higher stages is less in imperfect ADI sharing than no information sharing case. In other words, we can say that the impact of imperfect ADI sharing is visible in the upstream stages of the supply chain. During experimentation, we have collected feedback from the participants, which say that they tried to control the fluctuations in orders by using the imperfect ADI information. If the magnitude of variance of orders placed in a supply chain is more, there will be higher inventory or more shortages in that supply chain (Lee et al., 1997). This is observed in the present work also. The total inventory at each stage in the supply chain is more under no information sharing than with imperfect ADI sharing because the magnitude of variance of orders placed in the first case is higher than the second one. From Fig. 6 and t-test conducted for difference in means, we can say that the total holding cost of the supply chain with information sharing is lesser than with no information sharing. It has been found that the impact of ADI information sharing on fill rate is not significant in the experimental results (through t-test for fill rate). Magnitude of variance of orders placed at all stages is more or less the same, when (R, S) with safety stock inventory control policy is followed at each stage in the supply chain. Fill rate with this policy is 0.992 . From the present study, results of the $(R, S)$ inventory control policy cannot be generalized because the results obtained are from the analysis of a small period of time.

Finally, we can say that the imperfect ADI sharing improves the performance of the supply chain. The bullwhip effect could be observed under small lead time with no backorders. However, imperfect ADI reduces the bullwhip effect in the supply chain and improves its performance. The result of a role play game generally shows the behavioural aspect of the inventory order decision maker at each stage of the supply chain. It is observed that the bullwhip effect can be reduced by following (R, S) policy (with safety stock) at each stage with imperfect ADI sharing. It may be noted that in competitive environment, supply chain wants to have better fill rate. Under ADI, $(\mathrm{R}, \mathrm{S})$ policy 
with safety stock is able to estimate the uncertainty in inventory variation and is able to meet 0.992 fraction of the total demand arisen. But to get a better picture of the (R, S) policy with safety stock, a rigorous simulation with more number of periods and replications is required.

\section{Acknowledgement}

The authors are thankful to the post graduate students (2009-2011 batch) and Production Engineering under graduate students (2007-2011 batch) of NIT Calicut for participating in this experimental study.

\section{References}

Agrawal, S., Sengupta, R.N. \& Shankar, K. (2009). Impact of information sharing and lead time on bullwhip effect and on-hand inventory. European Journal of Operational Research, 192, 576593.

Bottani, E., Montanari, R. \& Volpi, A. (2010). The impact of RFID and EPC network on the bullwhip effect in the Italian FMCG supply chain. International Journal of Production Economics, 124, $426-432$.

Croson, R. \& Donohue, K., (2003). Impact of POS data sharing on supply chain management: an experiment. Production and Operations Management, 12(1), 1-12.

Croson, R. \& Donohue, K. (2006). Behavioral causes of the bullwhip effect and the observed value of inventory information. Management Science, 52 (3), 323-336.

Dejonckheere, J., Disney, S.M., Lambrecht, M.R. \& Towill, D.R. (2003). Measuring and avoiding the bullwhip effect: A control theoretic approach. European Journal of Operational Research, 147, 567-590.

Johnson, R.A., (2004). Probability and statistics for engineers . Prentice-Hall India.

Lee, H.L, Padmanabhan, V. \& Whang, S. (1997). The bullwhip effect in supply chains. Sloan Management Review, 38 (3), 93-102.

Lee, H.L, Padmanabhan, V. \& Whang, S. (2004). Information distortion in a supply chain: The bullwhip effect. Management Science, 50 (12), 1875-1885.

Metters, R., (1997). Quantifying the bullwhip effect in supply chains. Journal of Operations Management, 15, 89-100.

Montgomery, D.C. (2001). Introduction to statistical quality control. John Wiley \& Sons.

Siegel, S. \& Castellan, N.J., (1988). Nonparametric statistics for the behavioral sciences. McGraw Hill international editions.

Silver, E.A., Pyke, D.F. \& Peterson, R. (1998). Inventory management and production planning and scheduling. John Wiley \& Sons, New York.

Simchi-Levi, D., Kaminsky, P., Simchi-Levi, E. \& Shankar, R., (2008). Designing and Managing the Supply Chain - concepts, strategies and case studies. Tata McGraw-Hill.

Steckel, J.H., Gupta, S. \& Banerji, A. (2004). Supply chain decision making: will shorter cycle times and shared point-of-sale information necessarily help?. Management Science, 50 (4), 458-464.

Sterman, J.D. (1989). Modeling managerial behaviour: Misperceptions of feedback in a dynamic decision making experiment. Management Science, 35 (3), 321-339.

Sterman, J.D. (2009). "The Beer Game" available online at http://web.mit.edu/jsterman/www/SDG/beergame.html. (Accessed on May, 2009)

Sucky, E., (2009). The bullwhip effect in supply chains - An overestimated problem?. International Journal of Production Economics, 118, 311 - 322.

Tan, T., Gullu, R. \& Erkip, N. (2007). Modelling imperfect advance demand information and analysis of optimal inventory policies. European Journal of Operational Research, 177, 897-923.

Wang, X., Liu, Z., Zheng, C. \& Quan, C. (2008). The impact of Lead time on bullwhip effect in supply chain. IEEE transactions, 93-97.

Wu, D.Y. \& Katok, E. (2006). Learning, communication and bullwhip effect. Journal of Operations Management, 24, 839-850. 